\title{
COMPORTAMENTO HIGROSCÓPICO DO EXTRATO SECO DE URUCUM (Bixa Orellana L)
}

\author{
Hygroscopic behavior of annatto (Bixa Orellana $L)$ dried extract \\ George Carlos dos Santos Anselmo', Mário Eduardo R. M. Cavalcanti Mata², \\ Edson Rodrigues ${ }^{3}$
}

\begin{abstract}
RESUMO
Neste trabalho, objetivou-se determinar a higroscopicidade do urucum na forma de extrato seco. Neste estudo foram obtidas as atividades de água do extrato seco de urucum para as temperaturas de 10 a $50^{\circ} \mathrm{C}$ e teores de água entre 6 e $22 \%$ base úmida. A metodologia empregada para as determinações foi o método dinâmico em que se utilizou o equipamento Thermoconstanter Novasina TH-2. Para os resultados experimentais aplicaram-se as equações propostas por Henderson modificada por Thompson e Henderson modificada por Cavalcanti Mata e Peleg. Por meio das análises dos parâmetros encontrados concluiu-se que a equação que melhor se ajusta aos dados experimentais é a equação de Henderson modificada por Cavalcanti Mata e que as isotermas de adsorção de água do extrato de urucum seco se comportaram sigmoidalmente, sendo consideradas do tipo II.
\end{abstract}

Termos para indexação: Extrato seco de urucum, higroscopicidade, secagem, isotermas.

\section{ABSTRACT}

The objective of this work was to verify the higroscopicity of annatto seeds in the dry extract form. The isotherms were determined by the dynamic method with the Thermoconstanter Novasina TH-2 equipment. The equilibrium temperatures were 10 , $20,30,40$ and $50{ }^{\circ} \mathrm{C}$ to range of moisture content between 6 and 22\%, wet basis. The equations proposed by Henderson modified by Thompson and Henderson modified by Cavalcanti Mata and Peleg were applied to the experimental data. Through the gotten parameters found concluded that the best equation to represent the experimental data is the Henderson equations modified by Cavalcanti Mata. It was also concluded that hygroscopic equilibrium isotherms of annatto seeds presented sigmoid forms, considered type II.

Index terms: Dry extract of annatto seeds, hygroscopic equilibrium, drying, isotherms.

(Recebido em 20 de novembro de 2006 e aprovado em 6 de março de 2008)

\section{INTRODUÇÃO}

O urucueiro (Bixa orellana L.) é uma planta originária da América Tropical, também chamada de annatto (inglês), onoto (espanhol), rocou (francês) e orleansstrauch (alemão). Esta planta é encontrada nas diversas regiões do Estado da Paraíba, no entanto, foi no Brejo Paraibano que a sua exploração comercial ocorreu com maior intensidade. Na Paraíba, segundo a EMATER/ $\mathrm{PB}$, a produção atual está em torno de duas mil toneladas. Para a região Nordeste, a primeira colheita, a mais significativa, ocorre nos meses de junho e julho, enquanto que a segunda, conhecida como safrinha, realiza-se no período de novembro a dezembro.

O urucuzeiro tem grande importância para o desenvolvimento socioeconômico da Região Nordeste do
Brasil, pois $78,2 \%$ do seu cultivo provem da agricultura familiar, sob condições de sequeiro, com custos reduzidos de implantação, se comparados com outras culturas.

O urucuzeiro é uma planta que tem uma altura que varia entre de 2 a $9 \mathrm{~m}$, podendo ser considerada uma planta ornamental pela beleza e colorido de suas flores, além de ser produtora do corante natural de grande interesse comercial.

Os frutos são cápsulas armadas por espinhos maleáveis que se tornam vermelhas quando maduras. $\mathrm{Na}$ maturidade, no interior das cápsulas existem pequenas sementes dispostas em série, envolvidas por arilo vermelho. Das sementes de cor avermelhada, extrai-se o corante natural que é muito utilizado pelas indústrias da região, sendo parte comercializado no mercado interno (80\%) e outra parte é destinada à exportação (20\%).

\footnotetext{
'Engenheiro Agrícola, Mestrando - Departamento de Engenharia Mecânica - Universidade Federal de Campina Grande/UFCG - Rua Aprígio Veloso, 882 Bodocongó - 58109-900 - Campina Grande, PB - georgeanselmo@yahoo.com.br

2Engenheiro Agrícola, Doutor, Professor - Departamento de Engenharia Mecânica - Universidade Federal de Campina Grande/UFCG - Rua Aprígio Veloso, 882 - Bodocongó - 58109-900 - Campina Grande, PB - mata@deag.ufcg.edu.br

${ }^{3}$ Engenheiro Químico - Departamento de Engenharia Química - Universidade Federal de Campina Grande/UFCG - Rua Aprígio Veloso, 882 - Bodocongó 58109-900 - Campina Grande, PB - edinhoquimica@yahoo.com.br
} 
Sob o aspecto medicinal as sementes de urucum são consideradas sementes condimentares, tendo efeito estomacal, laxativo, cardiotônico, hipotensor expectorante e antibiótico, agindo como antiinflamatório para as contusões e feridas, apresentando, ainda, emprego interno na cura das bronquites e externo nas queimaduras.

Na culinária regional, é comum o uso do corante de urucum que tem a denominação de colorau. O seu consumo é estimado em 20 a 25 mil toneladas/ano e movimenta cerca de US\$12,0 milhões de dólares anuais, enquanto o extrato de corantes movimenta cerca de US\$ 4,8 milhões, e o pó e grãos em torno de US\$ 1,4 milhões (REBOUÇAS \& SÃO JOSÉ, 2006).

As sementes dessa planta se destacam como importante matéria-prima para a obtenção dos corantes bixina, norbixina e norbixato, em razão das suas características de produto natural, não tóxico, elevado poder tintorial e amplo espectro de cores, utilizados para coloração de produtos alimentícios, cosméticos, farmacêuticos e têxteis, além de serem usados como condimentos culinários (colorau).

As sementes do urucum contêm: celulose (40 - 45\%), açúcares $(3,5-5,2 \%)$, óleo essencial $(0,3 \%$ - 0,9\%), óleo fixo (3\%), pigmentos $(4,5-5,5 \%)$, proteínas (13 - 16\%), alfa e beta-carotenos e outros constituintes. Possuem também dois tipos de pigmentos, a orelhena de cor amarela e solúvel em água; e a bixina, de cor vermelha e solúvel em óleo. Conforme a Tabela 1, observa-se que a semente de urucum possui uma composição de minerais e vitaminas essenciais ao ser humano, tais como o cálcio e o ferro, e as vitaminas $\mathrm{A}, \mathrm{B} 1, \mathrm{~B} 2$ e $\mathrm{C}$.

A bixina é o pigmento presente em maior concentração nas sementes, representando mais de $80 \%$ dos carotenóides totais, sendo lipossolúveis e sujeitos à extração com alguns solventes orgânicos (BATISTA, 1988). Na indústria alimentícia, o corante das sementes de urucum é vendido na forma de extrato em diferentes concentrações.

Um dos processos de extração do pigmento das sementes de urucum é a extração aquosa. Neste processo, a extrato sai em forma de pasta que é posteriormente seca, gerando um extrato seco.
O extrato seco de urucum é, por sua vez, um produto extremamente higroscópico, ou seja, de acordo com as condições ambientais de armazenagem do produto e da impermeabilidade da embalagem, esse produto, tende a entrar em equilíbrio com as condições termodinâmicas do ar ambiente, perdendo ou ganhando água.

A umidade de um alimento é expressa pelo valor obtido na determinação da água total contida no mesmo. Entretanto, esse valor não fornece indicações de como a água está distribuída, bem como não permite saber se toda ela está ligada da mesma maneira. Desta forma, o conhecimento da distribuição da água no alimento é mais importante que simplesmente o conhecimento da umidade. A água em produtos biológicos é um dos fatores mais importantes para a sua conservação e armazenagem, influenciando sobre o sucesso, ou não, da manutenção da qualidade do produto e do seu tempo de duração em prateleira (QUAST, 1968).

A atividade de água $\left(\mathrm{a}_{\mathrm{w}}\right)$ é uma medida da quantidade de moléculas de água livres ou ativas, geralmente obtida em relação à pressão de vapor da água pura. Esta medida é de fundamental importância, visto que, por meio dela, podem ser previstas reações químicas e enzimáticas, e desenvolvimento de microrganismos. A partir do conhecimento da $a_{w}$ pode-se, também, propor sistemas adequados de embalagem para um produto (TEIXEIRA NETO et al., 1976).

Isotermas de adsorção de umidade descrevem a quantidade de água adsorvida por um produto, em dada temperatura, em função da $\mathrm{a}_{\mathrm{w}}$ ou da umidade relativa (GÓIS, 1981). Desta forma, o conhecimento do teor de água de equilibro quando submetido a diferentes condições de temperatura, é uma informação necessária para o armazenamento do produto.

Portanto, conduziu-se este trabalho, com o objetivo de determinar a atividade de água do extrato de urucum seco nas temperaturas de $10,20,30,40$ e $50{ }^{\circ} \mathrm{C}$ e teores de água variando de 6 a $22 \%$ base úmida; e determinar os coeficientes das equações propostas por Henderson modificada por Thompson, Henderson modificada por Cavalcanti Mata e Peleg.

Tabela 1 - Composição de minerais e vitaminas de 100g de semente de urucum.

\begin{tabular}{cccccc}
\hline Cálcio & $(\mathrm{mg})$ & 7,00 & Vitamina A & $(\mathrm{mmg})$ & 15,00 \\
\hline Fósforo & $(\mathrm{mg})$ & 10,00 & Vitamina B1 & - & - \\
\hline Ferro & $(\mathrm{mg})$ & 0,80 & Vitamina B2 & $(\mathrm{mg})$ & 0,05 \\
\hline Vitamina C & $(\mathrm{mg})$ & 2,00 & Niacina & $(\mathrm{mg})$ & 0,03 \\
\hline
\end{tabular}

Fonte: Empresa de Pesquisa agropecuária da Paraíba - EMEPA 


\section{MATERIAL E MÉTODOS}

O presente trabalho foi realizado no Laboratório de Processamento e Armazenamento de Produtos Agrícolas do Núcleo de Tecnologia em Armazenamento Departamento de Engenharia Agrícola - Centro de Tecnologia e Recursos Naturais da Universidade Federal de Campina Grande.

A amostra do urucum seco, foi seca em estufa (FANEM - Modelo 330), pelo método direto à (130ÚC por 24 horas), determinando-se seu teor de umidade. As pesagens foram em balança GEHAKA - Modelo BG 8000.

As isotermas de equilíbrio higroscópico foram obtidas no Laboratório de Transferência em Meios Porosos, do Departamento de Engenharia Química do Centro de Ciências e Tecnologia da UFCG, em Campina Grande - PB, utilizando-se o método dinâmico com o equipamento Thermoconstanter Novasina TH-2, Figura 1.

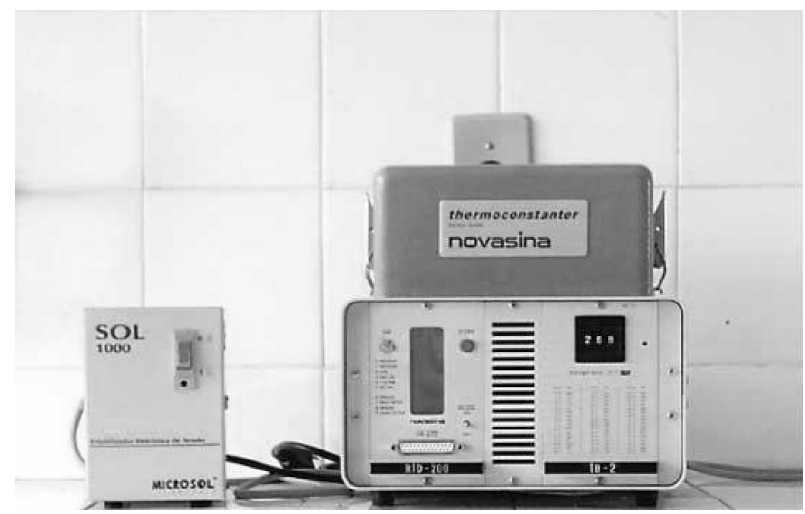

Figura 1 - Equipamento Thermoconstanter Novasina TH02, utilizado para determinação da atividade de água.

Aproximadamente, $1 \mathrm{~g}$ de cada amostra do urucum seco foram pesadas em cápsula e, em seguida, foram umedecidas em uma câmara contendo um becker com água, obedecendo a um tempo de 24 horas.

Em tempos regulares, as amostras foram pesadas e colocadas no equipamento, a fim de determinar a umidade de equilíbrio e a atividade de água para cada uma, a temperaturas de 10 a $50^{\circ} \mathrm{C}$.

\section{Equações das isotermas de equilíbrio higroscópico do} urucum seco

As equações utilizadas para expressar as isotermas de equilíbrio higroscópico do urucum seco encontram-se na Tabela 2, que foram equações Henderson modificada por Thompson e Henderson modificada por Cavalcanti Mata e Peleg. Os coeficientes dessas equações foram obtidos por regressão não linear, pelo método de Hookejeeves e Quase-Newton utilizando-se o programa computacional Stastica 7.1.

Tabela 2 - Equações de isotermas de equilíbrio higroscópico

\begin{tabular}{lc}
\hline \multicolumn{1}{c}{ Nomenclatura } & Modelos \\
\hline $\begin{array}{l}\text { Henderson } \\
\text { modificada por } \\
\text { Thompson }\end{array}$ & $x_{e}=\left[\frac{\ln \left(1-a_{w}\right)}{k(T+C)}\right]^{1 / N}$ \\
$\begin{array}{l}\text { Henderson } \\
\text { modificada por } \\
\text { Cavalcanti }\end{array}$ & $x_{e}=\left[\frac{\ln \left(1-a_{w}\right)}{k\left(T^{C}\right)}\right]^{1 / N}$ \\
Mata & $x e=\exp \left[k-C T+N \exp \left(A_{w}\right)\right]$
\end{tabular}

Fonte: Ciênc. Tecnol. Aliment., Campinas, v. 23, n. 2, May/ Aug. 2003.

em que,

$\mathrm{a}_{\mathrm{w}}=$ atividade de água, decimal;

$\mathrm{x}_{\mathrm{e}}=$ Teor de água de equilíbrio, \% base seca;

$\mathrm{C}, \mathrm{k}, \mathrm{N}$, = parâmetros que dependem da temperatura $\mathrm{e}$ natureza do produto.

\section{RESULTADOS E DISCUSSÃO}

Para a determinação das isotermas de equilíbrio higroscopico, foram realizadas pesagens regulares a cada tempo de exposição na estufa, partindo de um peso de $100 \mathrm{~g}$ até o peso desejado, que seria para cada teor de água na faixa de 6 a $22 \%$. O teor de umidade inicial do produto estava a $22 \%$ b.u. . Na Tabela 3, encontram-se os valores experimentais das isotermas de equilíbrio higroscópico do extrato de urucum nas temperaturas de 10 a $50^{\circ} \mathrm{C}$ e teor de água de equilíbrio de 6 a $22 \%$ base úmida.

Tabela 3 - Dados experimentais das isotermas no intervalo de temperatura de 10 a $50^{\circ} \mathrm{C}$, de umidade de equilíbrio (Ue) e atividade de água $\left(\mathrm{a}_{\mathrm{w}}\right)$

\begin{tabular}{cccccc}
\hline $\begin{array}{c}\text { Ue \% } \\
\text { base úmida }\end{array}$ & $\begin{array}{c}\mathrm{a}_{\mathrm{w}} \\
50^{\circ} \mathrm{C}\end{array}$ & $\begin{array}{c}\mathrm{a}_{\mathrm{w}} \\
40^{\circ} \mathrm{C}\end{array}$ & $\begin{array}{c}\mathrm{a}_{\mathrm{w}} \\
30^{\circ} \mathrm{C}\end{array}$ & $\begin{array}{c}\mathrm{a}_{\mathrm{w}} \\
20^{\circ} \mathrm{C}\end{array}$ & $\begin{array}{c}\mathrm{a}_{\mathrm{w}} \\
10^{\circ} \mathrm{C}\end{array}$ \\
\hline 6 & 0,044 & 0,044 & 0,115 & 0,133 & 0,080 \\
8 & 0,059 & 0,059 & 0,122 & 0,184 & 0,096 \\
10 & 0,075 & 0,075 & 0,130 & 0,209 & 0,114 \\
12 & 0,092 & 0,092 & 0,138 & 0,236 & 0,132 \\
14 & 0,208 & 0,208 & 0,147 & 0,333 & 0,235 \\
16 & 0,341 & 0,341 & 0,201 & 0,434 & 0,388 \\
18 & 0,480 & 0,480 & 0,403 & 0,541 & 0,549 \\
20 & 0,626 & 0,626 & 0,633 & 0,652 & 0,717 \\
22 & 0,780 & 0,780 & 0,875 & 0,770 & 0,895 \\
\hline
\end{tabular}


Por meio dos resultados obtidos, que foram a atividade de água para cada temperatura em relação ao teor de água. Obtiveram-se valores de atividades de água que demonstram que para um dado teor de água em relação a um valor de temperatura, tem-se um valor de atividade de água, e, conforme a Tabela 3, constata-se que para a temperatura de $10^{\circ} \mathrm{C}$ obteve-se a maior atividade de água registrada para um teor de água de $22 \%$, enquanto para as temperaturas de 50 e $40^{\circ} \mathrm{C}$ obtiveram-se os menores valores de atividade de água. Esses dados, antes analisados representam o equilíbrio higroscópico do produto (Urucum Seco), e que, para cada temperatura e teor de água específico, existe um valor de atividade de água que proporciona um equilíbrio higroscópico, com resultados dependentes da equação utilizada, e que, para este trabalho, foram: Henderson modificada por Thompson e Henderson modificada por Cavalcanti Mata e Peleg. O equilíbrio higroscópico tem sua importância para a armazenagem de produtos agrícolas baseada no tempo de armazenagem, quando por meio de valores de temperatura e de atividade de água para um dado teor de água, pode-se ter uma idéia de quanto o produto pode absorver ou perder água.

Na Tabela 4, encontram-se os parâmetros das equações para cada modelo utilizado Henderson modificado por Thompson e Henderson modificado por Cavalcanti Mata e Péleg.

Por meio dos resultados obtidos, que foram a atividade de água para cada temperatura em relação ao teor de água. Obtiveram-se valores de atividades de água que demonstram que para um dado teor de água em relação a um valor de temperatura, tem-se um valor de atividade de água, e, conforme a Tabela 3, constata-se que para a temperatura de $10^{\circ} \mathrm{C}$ obteve-se a maior atividade de água registrada para um teor de água de $22 \%$, enquanto para as temperaturas de 50 e $40^{\circ} \mathrm{C}$ obtiveram-se os menores valores de atividade de água. Esses dados, antes analisados representam o equilíbrio higroscópico do produto (Urucum Seco), e que, para cada temperatura e teor de água específico, existe um valor de atividade de água que proporciona um equilíbrio higroscópico, com resultados dependentes da equação utilizada, e que, para este trabalho, foram: Henderson modificada por Thompson e Henderson modificada por Cavalcanti Mata e Peleg. O equilíbrio higroscópico tem sua importância para a armazenagem de produtos agrícolas baseada no tempo de armazenagem, quando por meio de valores de temperatura e de atividade de água para um dado teor de água, pode-se ter uma idéia de quanto o produto pode absorver ou perder água.

$\mathrm{Na}$ Tabela 4, encontram-se os parâmetros das equações para cada modelo utilizado Henderson modificado por Thompson e Henderson modificado por Cavalcanti Mata e Péleg.

Tabela 4 - Parâmetros das equações de Henderson modificado por Tompson, Henderson modificado por Cavalcanti Mata e Peleg para o extrato seco de urucum.

\begin{tabular}{lrrrr}
\hline \multicolumn{1}{c}{ Equações } & \multicolumn{4}{c}{ Extrato de urucum } \\
\hline \multicolumn{1}{c}{$\mathrm{k}$} & $\mathrm{C}$ & $\mathrm{N}$ & $\mathrm{R}^{2}$ \\
\hline $\begin{array}{l}\text { Henderson } \\
\text { modificado } \\
\text { por Tompson }\end{array}$ & $-0,00463$ & 47380,4 & 0,31735 & 0.829 \\
$\begin{array}{l}\text { Henderson } \\
\text { modificado } \\
\text { por Cavalcanti }\end{array}$ & $-0,00107$ & 0,5435 & 0,33862 & 0.931 \\
$\begin{array}{l}\text { Mata } \\
\text { Peleg }\end{array}$ & 1,3365 & $-0,0063$ & 0,7061 & 0,812 \\
\hline
\end{tabular}

Na Figura 2 (a,b e c), encontra-se a distribuição dos resíduos em função dos valores calculados para as 3 equações delineadas para representar as isotermas de equilíbrio higroscópico do extrato de urucum. Nessas figuras, observa-se que os resíduos da equação proposta por Peleg têm uma distribuição tendenciosa, das equações de Henderson, modificada por Cavalcanti Mata e Henderson, modificado por Thompson em uma distribuição aleatória. No entanto, a dispersão dos resíduos na equação de Henderson modificada por Thompson é bem maior do que a equação de Henderson modificada por Cavalcanti Mata. Desta forma, embora os coeficientes de determinação, não sejam satisfatórios, de modo a indicar que uma das equações estudadas expressa satisfatoriamente as isotermas de equilíbrio higroscópico do extrato de urucum, pode-se afirmar que das equações analisadas a que melhor representa essas isotermas é a proposta por Cavalcanti Mata. 


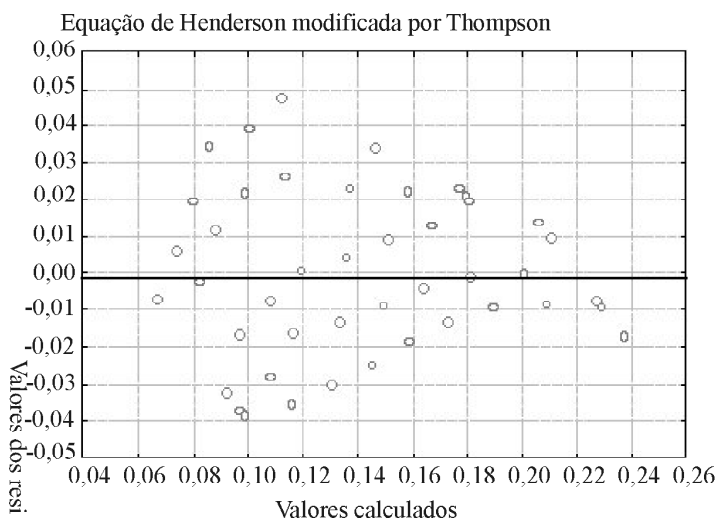

(A)

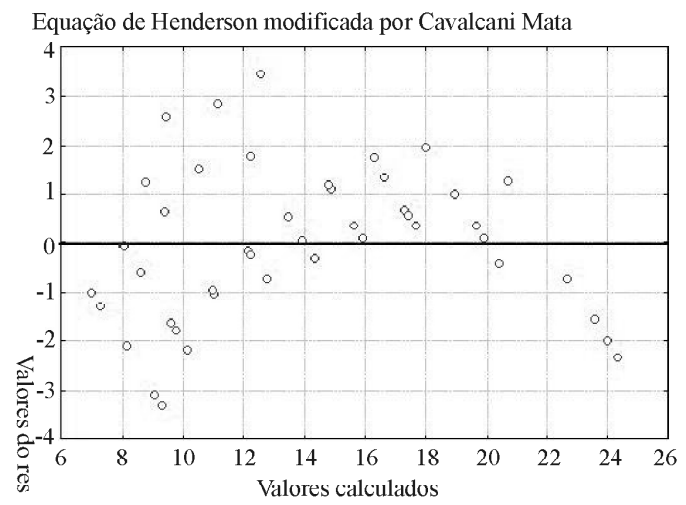

(B)

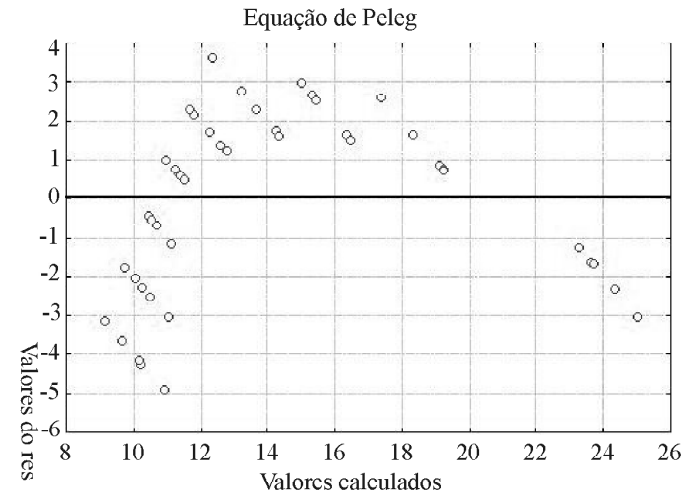

( C )

Figura 2 (A, B e C) - Distribuição dos resíduos em função dos valores calculados para as equações de Henderson modificada por Thompson (A), Henderson modificada por Cavalcanti Mata (B) e Peleg (C) utilizadas para definir as isotermas de equilíbrio higroscópico do extrato de urucum.

\section{CONCLUSÕES}

Diante dos resultados obtidos nesta pesquisa experimental, quando se verificou a higroscopicidade do extrato de urucum concluiu-se que:

Das equações testadas, a Henderson modificada por Cavalcanti Mata foi a que melhor representou as isotermas de equilíbrio higroscópico do extrato seco de urucum;

Na temperatura de $50^{\circ} \mathrm{C}$ observou-se os menores valores de atividade para os teores de água de 6 a 22\%;

As isotermas de adsorção de umidade do extrato seco de urucum se comportam sigmoidalmente, sendo consideradas do tipo II;

Os dados de equilíbrio de adsorção, obtidos para o pó indicam que o produto apresenta baixa higroscopicidade;

A umidade de equilíbrio diminui com o aumento da temperatura, indicando mudanças nos mecanismos de interação da água com os sítios de superfície do produto, ou nos próprios sítios.

\section{AGRADECIMENTOS}

Ao CNPq pela bolsa de Iniciação Científica.

\section{REFERÊNCIAS BIBLIOGRÁFICAS}

BATISTA, F. A. S. Urucueiro: instruções práticas para implantação e condução de um plantio. João Pessoa: EMEPA-PB/EMATER-PB, 1988. 26 p. (Circular técnica, 3).

GÓIS, V. A. de. Comportamento higroscópico do mamão liofilizado com vistas ao estabelecimento do seu potencial de “caking”. 1981. 114 f. Dissertação (Mestrado) - Escola Superior de Agricultura de Lavras, Lavras, 1981.

QUAST, D. G. Físico-química da água em alimentos desidratados. Boletim do Centro Tropical de Pesquisas e Tecnologia de Alimentos, v. 13, p. 1-25, 1968.

REBOUÇAS, T. N. H.; SÃO JOSÉ, A. R. A cultura do urucum: práticas de cultivo e comercialização. Vitória da Conquista: [s.n.], 1996. 42 p.

TEIXEIRA NETO, R. O.; DENIZO, N.; QUAST, D. G. Atividade de água em alguns alimentos de teor intermediário de umidade II. Coletânea do Instituto de Tecnologia de Alimentos, v. 7, p. 191-207, 1976. 